\title{
ANALISIS TENDANGAN SABIT PADA PERGURUAN PENCAK SILAT TAPAK SUCI DI KOTA BENGKULU
}

\section{Fani Marlianto}

PENJAS FKIP UNIB, e-mail: fanimarlianto2003@gmail.com

\author{
Yarmani \\ Universitas Bengkulu \\ Ari Sutisyana \\ Universitas Bengkulu \\ Defliyanto \\ Universitas Bengkulu
}

\begin{abstract}
Abstrak
Penelitian ini bertujuan untuk mengetahui tendangan sabit seluruh perguruan pencak silat Tapak Suci di Kota Bengkulu. Penelitian ini menggunakan metode penelitian desktiptif kualitatif. Dalam penelitian ini yang menjadi subyek penelitian adalah siswa perguruan pencak silat tapak suci . yang mendapatkan hasil yang sama pada tiga belas indikator mengenai tendangan sabit pada pada perguruan pencak silat Tapak Suci di Kota Bengkulu. hal ini tentunya menunjukan bahwa tendangan sabit pada perguruan pencak silat Tapak Suci semuanya mempunyai langkah dan gerakan yang sama. Sedangkan untuk analisis data berdasarkan tes kemampuan tendangan sabit mengambil objek pada ke tiga puluh (30) siswa perguruan tapak suci Kota Bengkulu. Hasil yang di peroleh dari tigapuluh (30) siswa dengan waktu 10 detik sehingga diperoleh berapa banyaknya tendangan sabit yang di dapatkan .skor sebesar 25-ke atas termasuk dalam kategori baik sekali sebanyak dua (2) orang atau sebesar 6,67\%, pada skor 20-24 yang termasuk dalam kategori baik sebanyak delapan belas (18) orang atau sebesar 60\%, untuk skor 17-19 di dalam kategori Cukup sebanyak 10 orang atau sebesar 33\%, untuk 15-16 di dalam kategori kurang tidak ada atau sebesar $0 \%$. Dan untuk kategori kurang sekali dengan skor 14-ke bawah juga tidak ada atau sebesar $0 \%$. Berdasarkan hasil analisis tersebut dapat disimpulkan bahwa kemampuan tendangan sabit yang dimiliki oleh siswa perguruan pencak silat Tapak Suci di Kota Bengkulu masuk dalam rata-rata kategori baik dengan persentase $60 \%$
\end{abstract}

Kata kunci : Tendangan Sabit ,Tapak Suci, Kota Bengkulu 


\begin{abstract}
This study aims to determine the sickle kick of all martial arts colleges in the city of Bengkulu. This research uses descriptive qualitative research method. In this research, the subject of research is the martial arts pencak silat college students. Who got the same results on thirteen indicators on sickle kicks at the martial arts college in Bengkulu City. This certainly shows that the sickle kick at the martial arts college Tapak Suci all have the same steps and movements. While for data analysis based on test of sickle cycling ability take object at thirty (30) student of sacred treadmill of Bengkulu City. The result is obtained from thirty (30) students with time 10 seconds so that obtained how many sickle kick get. Of 25-over are included in the excellent category of two (2) persons or equal to 6.67\%, on the score of 20-24 which fall into either the eighteen (18) or 60\% category for the score 17-19 In the category Quite as many as 10 people or by 33\%, for 15-16 in the category of less absent or by 0\%. And for the once less category with a 14-down score is also absent or 0\%. Based on the results of the analysis can be concluded that the ability of sickle kick owned by students of martial arts college in the City of Bengkulu Tapak entered the average category either with a percentage of $60 \%$
\end{abstract}

Keywords: Sickle Kick, Tapak Suci, City of Bengkulu

\section{PENDAHULUAN}

Olahraga merupakan segala bentuk aktivitas fisik jasmani dan rohani yang dilakukan dengan maksud untuk memelihara kesehatan dan memperkuat otot-otot tubuh.Kegiatan ini dalam perkembangannya dapat dilakukan sebagai kegiatan yang menghibur, menyenangkan atau juga dilakukan dengan tujuan untuk meningkatkan prestasi. Kementerian Negara Pemuda dan Olahraga Republik Indonesia, "Olahraga prestasi dimaksudkan sebagai upaya untuk meningkatkan kemampuan dan potensi olahragawan dalam rangka meningkatkan harkat dan martabat bangsa".

Indonesia adalah Negara yang kaya akan seni dan budaya mulai dari tari, adat istiadat, beladiri pencak silat dan lainnya. Hampir di semua wilayah Indonesia pasti memiliki ragam seni, ragam budaya dan ciri khas masing-masing yang sekaligus juga sebagai penggambaran dari wilayah itu sendiri. Seni beladiri pencak silat adalah salah satu seni budaya yang sedang berkembang pesat di Indonesia.

Pencak silat adalah budaya nenek moyang yang masih melekat dan termasuk salah satu seni budaya bangsa Indonesia. Pencak silat adalah budaya asli bangsa Indonesia. Para pendekar dan pakar pencak silat meyakini bahwa masyarakat Melayu menciptakan dan menggunakan ilmu beladiri sejak masa prasejarah. Pada masa prasejarah manusia harus menghadapi alam yang keras untuk tujuan survive dengan melawan binatang buas, dan pada akhirnya dikembangkan menjadi gerak-gerak bela 
serang. Seiring berjalannya waktu, kini pencak silat merupakan kesatuan dari empat aspek yaitu sebagai aspek spiritual, seni budaya, bela diri dan olahraga. Pencak, dapat mempunyai arti gerak dasar bela diri, yang terikat pada suatu peraturan dalam belajar, berlatih dan pertunjukkan. Sedangkan silat, mempunyai arti suatu gerak bela diri yang bersumber pada kerohanian murni, guna keselamatan diri dan kesejahteraan bersama dalam suatu sistem kehidupan bermasyarakat. Lubis (2014:1)Disamping itu, selain di Indonesia terdapat IPSI (Ikatan Pencak Silat Indonesia) sebagai induk organisasi silat di Indonesia. Dengan beranggotakan khusus IPSI secara otomatis 10 perguruan pencak silat historis, meliputi :

1 Persaudaraan Setiah Hati (PSH)

2 Persaudaraan Setia Hati Terate (PSHT)

3 Perisai Diri (PD)

4 Merpati Putih (MP)

5 Tapak Suci (TS)

6 Pajajaran

7 Persatuan Pencak Indonesia (PERPI HARIMURTI)

8 Terlat Sakti

9 Persinas ASAD

10 Nusantara

Tendangan merupakan teknik dan taktik serangan yang dilaksanakan dengan menggunakan tungkai dan kaki sebagai komponen menyerang. Serangan dengan menggunakan kaki yang bertujuan untuk mengenai atau menjatuhkan lawan agar memperoleh point dalam suatu pertandingan pencak silat. Notoesoejitno (1997: 71). Ada beberapa teknik dasar tendangan dalam pencak silat. Namun, hanya beberapa tendangan yang digunakan dalam kategori tanding, yaitu tendangan depan, tendangan $t$, tendangan belakang, dan tendangan sabit. Keempat tendangan ini merupakan tendangan yang sering digunakan dalam pertandingan kategori laga. Dari beberapa teknik dasar yang ada dalam olahraga pencak silat tendangan sabit merupakan teknik yang banyak di gunakan saat pertandingan. Oleh karena itu seorang siswa harus memiliki tendangan sabit yang baik dan tepat agar dapat memperoleh point.

Dalam pertandingan pencak silat, tendangan sabit merupakan bentuk serangan yang sering kali menghasilkan poin atau angka yang lebih jelas dan telak dibandingkan dengan serangan lainnya.

\section{METODE}

Jenis penelitian yang digunakan dalam penelitian ini adalah jenis penelitian deskriptif. Menurut Arikunto (2010: 3) "penelitian deskriptif adalah penelitian yang dimaksudkan untuk menyelidiki keadaan, kondisi atau hal-hal yang sudah disebutkan yang hasilnya dipaparkan dalam bentuk laporan penelitian".Penelitian lapangan yang bersifat deskriptif analisis yang menggunakan pendekatan kualitatif. Maksudnya adalah sumber data yang diperoleh dari siswa Perguruan Silat Tapak Sucidi Kota Bengkulu yang terkait dalam penelitian ini. Deskriptif adalah hanya ingin menggambarkan situasi yang sedang berlangsung, tanpa penguji hipotesis. Metode yang digunakan adalah survey yaitu pengumpulan data di lapangan Sugiyono (2006: 6) menyatakan bahwa metode survey digunakan untuk mendapatkan data dari tempat tertentu yang alamiah (bukan buatan), tetapi peneliti melakukan perlakuan dalam pengumpulan data, misalnya dengan observasi wawancara dan tes kemampuan tendangan sabit. Dalam penelitian ini akan 
diungkapkan/digambarkan tentang Analisis Tendangan Sabit Pada Siswa Perguruan Pencak Silat Tapak SuciDi Kota Bengkulu.Tempat Penelitian ,Penelitian dilakukan di Kota Bengkulu. Waktu Penelitian ,Penelitian dilakukan selama 1 bulan terhitung sejak dikeluarkanya surat izin meneliti hingga batas waktu yang ditentukan. Mengambil subyek dalam penelitian ini menggunakan teknik purposive, yaitu dengan memilih orangorang yanng diangggap tahu tentang fokus masalah dengan pengambilan keputusan seperti pelatih dan siswa Perguruan Pencak silat Tapak Suci. Kemudian dipadukan dengan teknik snowball sampling, yaitu meminta informan sebelumnya untuk menunjukan orang-orang yang dapat dijadikan informan. Sugiyono (2006: 246) Penelitian ini mengambil obyek penelitian seluruh yang berhubungan dengan tendangan sabit . siswa dan pelatih Menurut Sanafiah Faisal dalam Sugiyono (2006: 328) dalam mengambil subyek dan obyek penelitian harus yang memahami dan yang tergolong masih berkecimpung atau terlibat dalam kegiatan yang akan diteliti. Teknik Pengumpulan Data menggunakan Observasi, Observasi adalah Observasi sebagai teknik pengumpulan data mempunyai ciri yang spesifik bila di bandingkan dengan teknik yang lain, yaitu wawancara dan kuesioner selalu berkomunikasi dengan orang, maka observasi tidak terbatas pada orang, tetapi juga obyek-obyek alam yang lain. Sutrisno Hadi (1986) dalam Sugiyono (2006:162) mengemukakan bahwa. Observasi merupakan suatu proses yang kompleks, suatu proses yang tersusun dari berbagai proses biologis dan psikologis. Dua di antara yang terpenting adalah proses-proses pengamatan dan ingatan .Teknik pengumpulan data dengan observasi digunakan bila, penelitian berkenaan dengan perilaku manusia, proses kerja, gejala-gejala alam dan bila responden yang diamati tidak terlalu besar. Sugiyono (2006:162)Kemudian Wawancara, Wawancara digunakan sebagai teknik pengumpulan data apabila peneliti ingin melakukan studi pendahuluan untuk menemukan masalah yang harus di teliti, dan juga apabila peneliti ingin mengetahui hal-hal dari responden yang lebih mendalam dan jumlah respondennya sedikit. Instrumen Penelitian Instrumen tendangan sabit dalam penelitian ini dibuat atau dimodifikasi untuk mengukur siswa secara individu bukan beregu . Penelitian ini menggunakan rangkaian tes kemampuan tendangan sabit pada pencak silat menurut Lubis (2014:171) Pengukuran Kecepatan Tendangan Sabit Prosedur Pelaksanaan : Siswa bersiap-siap berdiri di belakang hand box/sandsack dengan satu kaki tumpu berada di belakang garis sejauh $50 \mathrm{~cm}$ (putri) $60 \mathrm{~cm}$ (putra). Pada saat aba-aba 'ya', siswa melakukan tendangan dengan kaki kanan dan kembali ke posisi awal dengan menyentuh lantai yang berada di belakang garis, kemudian melanjutkan tendangan kanan secepatcepatnya sebanyak-banyaknya selama 10 detik. Demikian juga dengan kaki kiri. Pelaksanaan dapat dilakukan 3 kali dan diambil berdasarkan banyaknya tendangan yang dilakukan selama 10 detik dengan ketinggian hand box/sandsack $75 \mathrm{~cm}$ (putri) $100 \mathrm{~cm}$ (putra) Penilaiian Skor Berdasarkan banyaknya tendangan siswa selama 10 detik. Teknik Analisis Data pada penelitian ini menggunakan Member Check Adalah proses pengecekan data yang diperoleh peneliti kepada pemberi data. Apabila data yang ditemukan disepakati oleh pemberi data berarti data tersebut sudah valid, sehingga semakin kredibel atau dipercaya, tetapi apabila data yang ditemukan peneliti dengan berbagai penafsirannya tidak 
disepakati oleh pemberi data, maka peneliti perlu melakukan diskusi dengan pemberi data, dan apabila perbedaanya tajam, maka peneliti harus merubah temuannya, dan harus menyesuaikan dengan apa yang diberikan oleh pemberi data yaitu Analisis Tendangan Sabit Pada Perguruan Pencak Silat Tapak SuciDi Kota Bengkulu .Triangulasi adalah teknik pengumpulan data yang bersifat menggabungkan dari berbagai teknik pengumpulan data dan sumber data yang telah ada.Setelah semuanya diperoleh dalam penelitian ini, data diolah dengan menggunakan statistik deskriptif (tabulasi frekuensi) dengan cara hanya mendeskripsikan hasil temuan yang diperoleh dari pengukuran (tes) terahadap kemampuan tendangan sabit. Dengan rumus menurut Anas Sudjono dalam Eko Bima Nugraha (1995: 40) :

$$
P=\frac{f}{n} \times 100 \%
$$

Keterangan :

$\mathrm{P}=$ presentasi $\mathrm{F}=$ frekuensi $\mathrm{N}=$ jumlah sampel

\section{Hasil dan Pembahasan}

Hasil

Pada penelitian ini membahas tentang tendangan sabit pada perguruan pencak silat Tapak Suci di Kota Bengkulu yang mendapatkan hasil yang sama pada tiga belas indikator mengenai tendangan sabit pada pada perguruan pencak silat Tapak Suci di Kota Bengkulu. hal ini tentunya menunjukan bahwa tendangan sabit pada perguruan pencak silat Tapak Suci semuanya mempunyai langkah dan gerakan yang sama. Sedangkan untuk analisis data berdasarkan analisis deskripsi mengambil objek pada ke tiga puluh (30) siswa perguruan tapak suci Kota Bengkulu. Hasil yang di peroleh dari tiga puluh (30) subjek informan didapatkan hasil tendangan sabit dengan waktu 10 detik sehingga diperoleh skor sebesar 25-ke atas termasuk dalam kategori baik sekali sebanyak dua (2) orang atau sebesar 6,67\%, pada skor 20-24 yang termasuk dalam kategori baik sebanyak delapan belas (18) orang atau sebesar $60,00 \%$, untuk skor 17 19 di dalam kategori Cukup sebanyak 10 orang atau sebesar 33,33\%, untuk 15-16 di dalam kategori kurang tidak ada atau sebesar 0,00\%. Dan untuk kategori kurang sekali dengan skor 14-ke bawah juga tidak ada atau sebesar 0,00\%. Berdasarkan hasil analisis tersebut dapat disimpulkan bahwa kemampuan tendangan sabit yang dimiliki oleh siswa perguruan pencak silat Tapak Suci di Kota Bengkulu masuk dalam rata-rata kategori baik dengan persentase $60,00 \%$.

\section{Pembahasan}

Hasil dari penelitian tersebut dapat diinterprestasikan bahwa ada beberapa faktor yang dapat mempengaruhi baik dan buruknya tendangan sabit pada perguruan yaitu :

1. Kurangnya waktu siswa dalam mendalami tendangan sabit dibidang pencak silat tapak suci. Karena latihan pencak silat hanya 1 kali dalam seminggu dengan latihan selama 1 jam dalam satu kali latihan. Tentu saja waktu tersebut sangat kurang.

2. Dengan jarangnya mengulan kembali latihan sehingga dasar dalam tendangan sabit yang dimiliki oleh siswa.

3. Postur tubuh yang tidak sama atau berbeda-beda, serta memiliki perbedaan lengan dan tungkai yang panjang. Sehingga mempengaruhi hasil yang diperoleh siswa.

4. Tingkat pengetahuan siswa mengenai tendangan sabit yang benar juga 
berbeda-beda. sehingga penerimaan materi pencak silat tiap siswa berbeda. Ada yang bisa mencerna dan menirukan gerakan dengan sekali demonstrasi, ada yang harus melihat demonstrasi berulang kali sampai gerakan tersebut terserap dengan sempurna.

\section{SIMPULAN DAN SARAN}

\section{Simpulan}

Pada penelitian ini membahas tentang tendangan sabit pada perguruan pencak silat Tapak Suci di Kota Bengkulu yang mengambil subjek penelitian pada perguruan pencak silat tapak suci. yang mendapatkan hasil yang sama pada tiga belas indikator mengenai tendangan sabit pada pada perguruan pencak silat Tapak Sucidi Kota Bengkulu. hal ini tentunya menunjukan bahwa tendangan sabit pada perguruan pencak silat Tapak Suci semuanya mempunyai langkah dan gerakan yang sama. Sedangkan untuk analisis data berdasarkan analisis deskripsi mengambil objek pada ke tiga puluh (30) siswa perguruan tapak suci Kota Bengkulu. Hasil yang di peroleh dari tigapuluh (30) subjek informan didapatkan hasil tendangan sabit dengan waktu 10 detik sehingga diperoleh skor sebesar 25-ke atas termasuk dalam kategori baik sekali sebanyak dua (2) orang atau sebesar $6,67 \%$, pada skor 20-24 yang termasuk dalam kategori baik sebanyak delapan belas (18) orang atau sebesar $60,00 \%$, untuk skor 17 19 di dalam kategori Cukup sebanyak 10 orang atau sebesar $33,33 \%$, untuk $15-16$ di dalam kategori kurang tidak ada atau sebesar 0,00\%. Dan untuk kategori kurang sekali dengan skor 14-ke bawah juga tidak ada atau sebesar $0,00 \%$. Berdasarkan hasil analisis tersebut dapat disimpulkan bahwa kemampuan tendangan sabit yang dimiliki oleh siswa perguruan pencak silat Tapak
Sucidi Kota Bengkulu masuk dalam rata-rata kategori baik dengan persentase $60 \%$. Saran

Setelah melakukan penelitian tentang "Analisis Tendangan Sabit Pada Perguruan Silat IPSI Di Kota bengkulu", maka penuis memberikan saran-saran sebagai berikut:

1 Perlunya latihan yang intensif pada setiap minggunya sehingga tendangan sabit pada perguruan pencak silat Tapak Suci Kota Bengkulu lebih baik

2 Perlunya penguasaan terhadap dasar-dasar gerakan tendangan sabit pencak silat perguruan tapak suci Kota Bengkulu, sehingga dalam melakukan gerakan tendangan sabit siswa mampu lebih baik lagi.

3 Dari hasil penelitian ini hendaknya menjadi masukan baru bagi peneliti lain untuk melakukan penelitian berhubungan dengan Analisis Tendangan Sabit Pada Perguruan Pencak Silat Tapak Suci di Kota Bengkulu.

\section{DAFTAR PUSTAKA}

Arikunto Suharsimi. (2010). Prosedur Penelitian Suatu pendekatan Praktik. Jakarta : PT Rineka Cipta

Bima Eko Nugraha (2014) Analisis Kecepatan Tendangan Pencak Silat Pada Pesilat Unit Kegiatan Mahasiswa Universitas Mulawarman. Samarinda: Universitas Mulawarman

Evi Yunika (2016) Harmonisasi Perguruan Pencak Silat Bengkulu Dalam Mendukung Prestasi Pencak Silat Di Bawah Naungan IPSI Provinsi 
Bengkulu. Bengkulu: Universitas Bengkulu

Lubis Johansyah (2014). Pencak Silat. Jakarta: PT Raja Grafindo Persada

M. Mustavid Almustahab (2016) Pengaruh Latihan stretching statis Terhadap Hasil Tendangan Sabit Pada Atlet Putra Pencak Silat Persinas Asad Lampung Selatan. Lampung: Universitas Negeri Lampung

Mulyana. (2014). Pendidikan Pencak Silat Membangun Jati Diri dan Karakter Bangsa. Bandung: PT Remaja Rosdakarya

Murhananto. (1993) Menyelami Pencak Silat. Jakarta: PT Penebar Swadaya

Notosoejitno. (1997). Khazanah Pencak Silat. Jakarta: CV Sagung Seto

Setyo Erwin. (2015). Pencak Silat. Yogyakarta: PT. Pustaka Baru
Sugiyono. (2006). Metode Penelitian Kuantitatif, Kualitatif Dan $R \& D$. Bandung: Alfabeta

Sugiyono. (2011). Metode Penelitian Kuantitatif, Kualitatif Dan $R \& D$. Bandung: Alfabeta.

Tangkudung, James. (2012). Kepelatihan Olahraga Pembinaan Prestasi Olahraga. Jakarta: Cerdas jaya ,(2016).Macam-macam

Metodologi Penelitian. Jakarta: Lensa Media Pustaka Indonesia (2018). Sport Psychometrics Dasar-dasar dan instrument Psikometri. Depok :Rajagrafindo persada.

Wardoyo Hendro. (2014). Pencak Silat. Jakarta: PT Raja Grafindo Persada 